\title{
MANUEL GÓMEZ MORÍN Y LA EDUCACIÓN: SU VISIÓN DE LA UNIVERSIDAD
}

José Manuel Orozco*

RESUMEN: Hacia 1927, Manuel Gómez Morin reúne una serie de ensayos que posteriormente fueron publicados junto con los textos sobre la Universidad. Ve un país dividido y con graves problemas de injusticia, luchas entre los mexicanos, falta de nacionalismo humanista en México, durante el período de 1915 a 1934. Propone la necesidad de que la juventud se eduque en las ciencias bajo un sentido estético, que se oriente moralmente hacia la justicia. Defiende la idea de una autonomía universitaria dentro del Estado y no como espacio de excepción: la autonomía dentro y desde el Estado. Denuncia el materialismo, el marxismo dogmático, el estudiar para ganar dinero como única meta en la vida; sostiene que educar es enseñar a pensar, dialogar, analizar, investigar. Pide herramientas y tecnología, y configura una pedagogía que oriente, desde el saber, al servicio, bajo el sentido artístico y ético. Solamente así se superarán los grandes problemas nacionales que requieren soluciones nacionales: no imitar modelos extranjeros que no convienen a nuestra cultura.

শ্ৰ

ABSTRACT: About 1927, Manuel Gómez Morin compiled a series of essays which were later published along with essays regarding universities. In this compilation, he portrays Mexico (1915-1934) as a divided country with serious problems of injustice, internal fighting, and a lack of humanistic nationalism. He puts forth the need for scientific education with an esthetic basis morally oriented toward justice for Mexican youth. He justifies the idea of university autonomy within the State and not as an area of exception: autonomy within the State and from the State. He decries materialism, dogmatic Marxism, and studying solely for material gain in life. He believes that educating is teaching how to think, converse, analyze, and investigate. He insists on the need of tools and technology as well as establishes a knowledge and service

* Departamento Académico de Estudios Generales, ITAM. 
based pedagogy with an artistic and ethical foundation. According to him, Mexico will overcome its national problems solely in this manner through national solutions and not by copying foreign models unsuitable for our culture.

PALABRAS CLAVE: México, ideología nacional, valores, comunidad, diálogo, autonomía, Universidad, libertad.

KEY WORDS: Mexico, National Ideology, values, community, dialogue, autonomy, university, liberty.

RECEPCIÓN: 30 de agosto de 2012.

APROBACIÓN: 6 de diciembre de 2012. 


\section{MANUEL GÓMEZ MORÍN Y LA EDUCACIÓN: SU VISIÓN DE LA UNIVERSIDAD}

\section{En 1927, Manuel Gómez Morín reúne} una serie de ensayos que posteriormente fueron publicados junto con los textos sobre la Universidad. Constituyen sus reflexiones en torno al país en momentos posteriores a la turbulencia de la Revolución. En ellos da cuenta del espíritu que hay que forjar para que México encuentre su destino. Por un lado, tenemos los escritos donde refleja su posición anti-positivista, anti-intelectualista, y más proclive a un espiritualismo intuitivo. Ahí se nota su relación con el pensamiento de Antonio Caso. Luego están los escritos donde Gómez Morín reflexiona en torno a la naturaleza de la Universidad: la autonomía, el socialismo revolucionario, las humanidades y las ciencias, y la necesidad de educar a la juventud en la crítica, la investigación, despertando la inquietud y la perplejidad. La idea del dogmatismo, y peor aún, la del fanatismo, le parecen peligros que debemos erradicar de la educación universitaria.

A continuación presento un breve análisis de las ideas de Manuel Gómez Morín sobre la educación. No excluye su visión sobre los problemas de México en ese momento: entre 1915 y 1934. Al final, recojo algunos textos de la Conferencia ante la Federación de Estudiantes que Gómez Morín pronunciara en la Universidad Nacional y que se recogió en la serie Conferencias y Discursos, donde pide a los jóvenes que asuman un papel en el momento crucial de 1930. 
El objetivo es dar a conocer su pensamiento educativo, sus reflexiones sobre el país, y que se integre a la serie de pensadores que han estudiado y hablado sobre México, dejando, claro, una huella en nosotros.

\section{Iniciación $^{1}$}

Dice Manuel Gómez Morín:

"Hace unos cuantos años, en la desazón de un régimen político que agonizaba, un pequeño grupo inició formalmente la rebelión espiritual contra las doctrinas que entonces y desde hacía tiempo eran verdad obligatoria en México.

En el Ateneo de la Juventud, Vasconcelos, el maestro de Caso, Pedro Henríquez Ureña, Acevedo, Ricardo Gómez Robledo, Alfonso Reyes y otros pocos más, alzaron la bandera de una nueva actitud intelectual.

[...] El aislamiento forzado en que estaba la República por el curso de la lucha militar favoreció la manifestación de un sentido de autonomía. Poco podíamos recibir del extranjero. Razones militares y aun monetarias nos impedían el conocimiento diario y verídico de los sucesos exteriores y la importación de los habituales artículos europeos o yanquis de consumo material o intelectual. Tuvimos que buscar en nosotros mismos un medio de satisfacer nuestras necesidades de cuerpo y alma. Empezaron a inventarse elementales sustitutos de los antiguos productos importados.

Y con optimista estupor nos dimos cuenta de insospechadas verdades". 2

"Existía México. México como país con capacidades, con aspiración, con vida, con problemas propios. No sólo era esto una fortuita

${ }^{1}$ Todos los encabezados en cursivas son del texto de Manuel Gómez Morín. Los dejo como están porque son marcas para introducir a sus textos. No son entonces indicadores míos.

${ }^{2}$ Manuel Gómez Morín, 1915 y otros ensayos, 1973, México, Editorial Jus, p. 20. 
acumulación humana venida de fuera a explotar ciertas riquezas o a mirar ciertas curiosidades para volverse luego. No era nada más una transitoria o permanente radicación geográfica del cuerpo estando el espíritu domiciliado en el exterior. Y los indios y los mestizos y los criollos, realidades vivas, hombres con todos los atributos humanos. El indio, no mero material de guerra y de trabajo, ni el criollo producto de desecho social de otros países, ni el mestizo fruto ocasional, con filiación inconfesable, de uniones morganáticas entre extranjeros superiores y nativos sin alma.

¡Existían México y los mexicanos!"3

Lo primero que llama la atención es su reconocimiento a los pensadores del Ateneo de la Juventud, ${ }^{4}$ que no duda en calificar como una nueva generación que va de la mano con una nueva forma de pensar: la idea de la intuición como medio para sentir el arte, la armonía y el flujo de la vida, en lugar del mero cálculo racional de los saberes positivos. Y la comprensión de que los problemas de México derivaban

${ }^{3}$ Op. cit., p. 20. Octavio Paz dice en el Laberinto de la Soledad: "Quizá el disimulo nació durante la Colonia. Indios y mestizos tenían, como en el poema de Reyes, que cantar quedo, pues "entre dientes mal se oyen palabras de rebelión". El mundo colonial ha desaparecido, pero no el temor, la desconfianza y el recelo. Y ahora no solamente disimulamos nuestra cólera sino nuestra ternura. Cuando pide disculpas, la gente del campo suele decir "Disimule usted, señor". Y disimulamos. Nos disimulamos con tal ahínco que casi no existimos", Octavio Paz, El laberinto de la soledad, 1984, FCE, p. 39.

${ }^{4}$ Octavio Paz dice de los pensadores que se pronuncian contra la filosofía del régimen porfirista: "en la esfera de las ideas dos jóvenes, Antonio Caso y José Vasconcelos, emprendían la crítica de la filosofía del régimen. Su obra forma parte de la vasta renovación intelectual iniciada por el grupo llamado Ateneo de la Juventud", op. cit., pp. 125-6. Y Samuel Ramos, por su parte, habla de la importancia del "Ateneo de la Juventud", y dice: "La obra cultural del Ateneo de la Juventud, iniciada por el año de 1908, debe entenderse como una lucha contra la desmoralización de la época porfirista. Este movimiento intelectual revolucionario se adelantaba dos años a la revolución política que estalló en 1910. [...] Un precursor de estos acontecimientos era Justo Sierra, humanista, animador de la cultura mexicana como maestro de Historia y como ministro de Instrucción Pública [...] La vocación de cada uno de los ateneístas era heterogénea. Había humanistas como Pedro Henríquez Ureña; filósofos, como Antonio Caso y José Vasconcelos, el primero orientado hacia la enseñanza universitaria, y el segundo hacia la acción política; había ensayistas, como Alfonso Reyes, Julio Torri y Jesús Acevedo; críticos como Eduardo Colín; poetas, como González Martínez". Samuel Ramos, El Perfil del Hombre y la Cultura en México, 1993, Madrid, Colección Austral, Ciencias/Humanidades. Espasa Calpe, (quincuagésima cuarta reimpresión), p. 77. 
en buena medida de tener los ojos puestos en el "afuera": lo que venía de Europa o de los Estados Unidos. No solamente en lo que toca a las manufacturas, los bienes que se importaban en lugar de producirlos en México. Es importante ver el señalamiento claro en relación a las riquezas de la nación. No es una cuestión del cuerpo que habita en México, mientras el espíritu se moldea al modo exterior. Se trata de que mente y cuerpo se formen desde una visión mexicana. No importa si hay ideas que se adoptan de otras culturas; la posibilidad de pensar por nosotros mismos se descubre por vez primera. Pensar en nuestros indios y su capacidad de trabajo, nuestro mestizaje como condenado al fracaso o lo criollo como algo que debe ser eliminado por su elitismo o exclusivismo. La idea es que todos nos demos cuenta de que existe México, de que hay una entidad llamada "México", y que somos mexicanos. Lo que significa pensar hacia adentro en nuestros problemas, admitirlos y resolverlos. Tener el impulso suficiente para dar cuenta de lo que nos atañe, nuestro país.

\section{Dice Gómez Morín:}

"Y en el año de 1915, cuando más seguro parecía el fracaso revolucionario, cuando con mayor estrépito se manifestaban los más penosos y ocultos defectos mexicanos y los hombres de la Revolución vacilaban y perdían la fe, cuando la lucha parecía estar inspirada nomás por bajos apetitos personales, empezó a señalarse una nueva orientación.

[... La necesidad política y el ciego impulso vital, obligaron a los jefes de un bando a tolerar expresamente estos postulados que tácitamente el pueblo perseguía desde antes. El oportunismo y una profunda inspiración de algunos, permitieron el feliz cambio que estos nuevos propósitos vinieron a obrar en una revuelta que, para sus líderes mayores, era esencialmente política". ${ }^{5}$

Si bien la Revolución fue violenta, y el fracaso revolucionario se veía reflejado en la lucha entre caudillos, las matanzas, los apetitos per-

${ }^{5}$ Op. cit., pp. 20-1. 
sonales de lucro, que hacían perder la fe en la unidad de un fin superior que aglutinase a todos, el resultado comenzó a sugerir la necesidad de un arreglo político y una nueva orientación hacia propósitos superiores: la unidad, la felicidad de la gente, y nuevos liderazgos. Sin embargo, un sentimiento interno de obscuridad dejaba en el desamparo a las conciencias. Porque todos pensaban a la luz de Comte, Spencer, a través de Gabino Barreda y el darwinismo social. Las ideas de Justo Sierra por momentos iban a la deriva en relación con los científicos radicales del porfirismo. Había fracasado el régimen de Porfirio Díaz, la economía no iba bien, y por ende, la violencia cundía por doquier.

\section{Obscuridad}

"Las nuevas doctrinas predicadas entonces, coincidieron con postulados evidentes de la Revolución, encontrando campo propicio en el desamparo espiritual que reinaba en México después del fracaso cabal del porfirismo en la política, en la economía y en el pensamiento, y justificaron e ilustraron el libre desarrollo de tendencias profundas que animaban el espíritu revolucionario". ${ }^{6}$

Es decir, por un lado había una fe encarnada en un nacionalismo fuerte. La expresión artística de las obras artesanales de los indígenas mexicanos, los grandes murales de los artistas que plasmaban la visión de la patria, los atisbos y promesas de reivindicar las causas indias con el objeto de hacer justicia, eran parte de una mentalidad universalista incuestionable: los mexicanos sentían que había una posibilidad, una promesa, un poder ser de México y de los mexicanos. Pero, por otro lado, un vago sentimiento de fracaso y de pueblo destinado al fracaso. La mezcla de ese entusiasmo posrevolucionario con la idea de que somos un pueblo destinado al fracaso genera confusión, obscuridad. Aparte de todo, faltan auténticos maestros, disciplina, una solidez institucional en la vida política; y todo eso ha dificultado la visión crítica que se pide de los mexicanos. Por eso, agrega Gómez Morín:

$$
{ }^{6} \text { Op. cit., p. } 22 .
$$


"La falta de maestros y de disciplina y el apremio de la política, hicieron imposible toda labor crítica. Motivos biológicos determinaban la aceptación apresurada de fórmulas que luego, por los mismos motivos, debían abandonarse. El postulado admitido porque resolvía una situación cualquiera, resultaba contradictorio del principio adoptado para entender o explicar otras situaciones. [... ] Porque infortunadamente no sólo han existido obscuridad intelectual y desorientación política. También son parte de estos años un terrible desenfreno y una grave corrupción moral. ${ }^{7}$

[...] No roba ni mata ya la turba armada. Pero el mismo funcionario que decreta la muerte para el soldado ladrón de una gallina, se enriquece en el puesto y no vacila en mandar asesinar a su enemigo.

Al caudillo surgido de la necesidad y del entusiasmo con la virtud mínima del valor, sucede el ladino impreparado que escamotea el afán democrático y diciéndose encarnación del pueblo, justifica sus necesidades esgrimiendo en su defensa la noble y fundada convicción en el profundo acierto del instinto popular". 8

Hay desorientación política, falta de crítica, corrupción, desenfreno y ausencia de moralidad en la vida social. Se percibe que en México los funcionarios roban y que la justicia es para unos, pero no para todos, pues los que sancionan al pobre que roba para comer, al mismo tiempo asesinan a sus enemigos. Mientras sigue habiendo caudillos, jefes, caciques, la democracia palidece. Sin embargo - plantea Manuel Gómez Morín-, se tiene fe en el instinto popular que ha impulsado el movimiento revolucionario, y fe en que esa noche y obscuridad en

${ }^{7}$ Es evidente en todo lo que estamos citando que Manuel Gómez Morín se refiere a esos momentos de turbulencia en plena revolución. Nosotros ubicamos este análisis justo en el año de 1915, cuando la guerra entre las facciones está a punto de concretar el triunfo del bando carrancista, de modo que el autor no tiene en mente aún la Constitución de 1917, y claro, todo lo que es el desarrollo ulterior a los años de consolidación de las instituciones. Nos interesa, empero, que se comprenda el sentido de un pensamiento que denuncia la falta de ideología, escuelas y maestros, y que el despliegue del Ateneo parece prometer con el intuicionismo estético de Caso y las ideas de Vasconcelos. Gómez Morín piensa en la gema de criollos y mestizos, el genio del indio, más allá de nacionalismos populistas; y eso es muy importante. La denuncia de la corrupción moral es de una trascendencia vigente.

${ }^{8}$ Op. cit., p. 23-4. 
que estamos será superada. Hay, pues, una noche en que vivimos. Dice Gómez Morín:

"Este cambio se debe fundamentalmente a la noche espiritual en que vivimos. No salimos aún del estado mental de lucha que influenció a nuestra generación. La falta de definición es nuestro pecado capital.

Un día descubrimos que la Revolución tenía sobre todo fines económicos. Exaltamos la razón económica sobre las demás y a poco un grosero materialismo que invade hasta a los más jóvenes, se funda y justifica en aquella proclamación indiscriminada. Encarecimos la generosidad de la acción y las virtudes de la violencia, y luego en nombre de esa afirmación se hace la apología de la crueldad, de la violencia sin propósito". 9

La noche es la violencia en que estamos. La crueldad con la que unos matan a otros. La apología de esa misma crueldad como medio para avanzar en política. Más allá de nacionalismos populistas, que de nada sirven, se exalta un grosero materialismo histórico sin ver las bellas artes, lo que tiene verdadero valor estético. Es decir, a tono con la violencia revolucionaria, surge un nacionalismo que exalta una visión materialista de nuestra historia en lugar del valor estético e intelectual de otros modos artísticos. La razón es suplantada por ese instinto violento, y las bellas artes por expresiones materialistas o marxistas que muestran lo que "somos". A eso llama Gómez Morín el "pastiche popular" o la "reivindicación nacionalista de las aptitudes indias". Que no quiere decir que Manuel Gómez Morín no aprecie, por ejemplo, la importancia del muralismo mexicano. Lo que denuncia es ese exacerbado nacionalismo que hace del indio la promesa del país que, al mismo tiempo, lo somete a la miseria o la marginación. O la idea de un triunfo revolucionario que nada dice de la barbarie que la misma revolución engendró. A la fecha, diríamos, el texto es vivo. Sigue vigente la corrupción, la violencia, la saña con que se matan unos a otros, la injusticia hacia los pobres, y ese discurso triunfalista que, empero, no hace nación

${ }^{9}$ Op. cit., pp. 24-5. 
aunque sea nacionalista. Y uno que otro amoroso de lo indígena, pero que no hace realmente nada por sacar al indio de su postración.

Manuel Gómez Morín nos invita. He aquí su invitación.

\section{Invitación}

"En el penoso proceso de nuestra historia, los acontecimientos pasados parecen ordenarse siguiendo un sentido. La conquista y el régimen colonial, la independencia y la reforma; hasta las revueltas incesantes, hasta Santa Anna, son explicables. Podemos descubrir en ellos una teleología.

Los hechos actuales están también llenos de intención. Desde 1915, a pesar de la tiranía, a pesar de los asesinatos, a pesar de la concupiscencia y de la desesperante estupidez de los líderes, a pesar de la aridez mental y moral, cada vez parece más segura y más inminente la revelación de un sino, de un peculiar modo de ser, de una íntima razón que impulsa la historia de México.

[... En varias ocasiones ha parecido llegado el momento de la revelación. Así fue, por ejemplo, en 1920, cuando se inició con prestigio apostólico la obra de Vasconcelos. ${ }^{10}$

[...] Es difícil definir lo que sea una generación. Algunos pretenden que lo es todo grupo de hombres contemporáneos. Otros piensan que no el tiempo, sino el estilo, forma las generaciones. Otros creen que un acervo común de ideas, una forma peculiar de reacción, una obra colectiva, determinan la existencia de una generación.

La unidad de época, de manera o de acción, son a menudo sus aspectos externos; pero la esencia de las generaciones debe buscarse en otra parte [...] Es una especie de unidad biológica superior, trascen-

${ }^{10}$ Op. cit., p. 26. Como dijimos, los textos que ahora se citan aluden a momentos de 1915. Pero se atienden sucesos de 1920, como éste, en el que se habla de la gran obra educativa de Vasconcelos. En realidad, Gómez Morín escribió estas notas en 1926. Más adelante reflexiona sobre temas educativos y va desarrollando las ideas que forjan su proyecto de la acción nacional. 
dental; una 'consanguinidad' espiritual que se manifiesta lo mismo en las semejanzas que en las diferencias". ${ }^{11}$

Nos invita a forjar una nueva generación. Unida en creencias, sentimiento, estilo, convergencia con respeto a las desemejanzas, o sea, tolerante. Nos pide que tengamos bases educativas sólidas como las pensadas en el proyecto de José Vasconcelos, de forma que la educación sea el fundamento que sustente esa nueva generación que dé sentido a la acción nacional. Que nos unamos valorando la vida, fraternizando, yendo juntos. Hasta que una suerte de consanguinidad espiritual nos impulse a romper el individualismo y la violencia. Si algo interesa es hacer patria; mas ésta no se hace si cada uno va por su lado. Si no entendemos que hay que educarnos para construir una generación unida espiritualmente.

"Los que forman generación, resultan individualmente ensayos de adaptación al arquetipo, resultados -frustráneos por parciales- del trágico esfuerzo que el arquetipo desarrolla por realizarse plenamente en el individuo.

Fracasados una vez y otra vez, el arquetipo, el sino, renuevan el empeño de realización y siguen su lucha con el tiempo enemigo de realizaciones, porque realizar es cumplir, terminar, morir, dejar de ser, negar el tiempo en suma, que es emprender, prometer, iniciar, vivir, llegar a ser $[\ldots]$.

Una generación es un grupo de hombres que están unidos por esta íntima vinculación quizá imperceptible para ellos: la exigencia interior de hacer algo, y el impulso irreprimible a cumplir una misión que a menudo se desconoce". ${ }^{12}$

${ }^{11}$ Op. cit., pp. 25, 26, 27. Aquí vemos claramente el proyecto: tener una generación de hombres unidos por creencias, valores, formas de vida, nexos, comunes; todos bajo el impulso peculiar de una fuerza de cohesión que se manifiesta en la búsqueda de lo semejante por encima de lo diverso. Implica una forma común de plantear y resolver problemas; y sí, tiene que ver con formar grupo, tener ideas compartidas, una coexistencia de hacer obra colectiva. Respira un aire común y es producto de una generación. El esfuerzo de la cultura se orientará en el sentido de unir como grupo a los mexicanos.

${ }^{12}$ Op. cit., p. 27. 
Vinculación, cultura, llegar a ser algo juntos, impulso biológico y espiritual común, arquetipo exitoso donde lo que se planifique se concrete o realice: esos son los factores que harán posible canalizar las inquietudes de un pueblo hacia la atemperación de la agresividad, propiciando el "aire de familia" en el que todos los mexicanos podamos compartir suelo y destino. En realidad, las clases sociales no se unen, hay individualismo; los planes no se realizan o fallan los arquetipos o modelos de nación (quedan en mero diseño), porque no se logra la comunidad espiritual de creencias comunes, canalización de inquietudes y proyecto claro para todos. Para alcanzar eso se necesita educación. Pasar de ser un pueblo violento y fracasado a un pueblo vinculado y exitoso. Pasar del individualismo feroz al espíritu de comunidad. Ir de una atomización social a los aires de familia que nos unen. Y por eso, como lo dice desde el principio, la educación es fundamental. Ahí, repetimos, la mención de José Vasconcelos es muy importante.

Hace falta entonces disponer de una nueva generación de mexicanos. $\mathrm{O}$ en su caso, irla creando. Caminar juntos. Lo dice Gómez Morín:

"Todos deberían caminar juntos. Pero viven separados por la suspicacia y por su propia indefinición. Olvidan la empresa común y se 84 empeñan en destruirse afiliándose a banderas de momento [...] Es tiempo de alzar una bandera espiritual; dar el santo y seña que permita el mutuo reconocimiento.

Hace falta una definición de tendencia y de actitud; la afirmación de un valor siquiera, en torno del cual se reúnan los esfuerzos dispersos y contradictorios". ${ }^{13}$

Identificar los problemas del país; tener un programa para enfrentar esos problemas y resolverlos; unir los esfuerzos en un trabajo compartido, evitando la dispersión y los choques entre nosotros; disponer de una ideología unificadora, sin mitos, que permita dar salida a las dificultades sin demagogia o retórica, es la única forma de superar las contradicciones que estamos viviendo. Hoy, nos diría Gómez Morín, justo en el año 2012, hay un grupo de partidos que no reconocen la elección

${ }^{13}$ Op. cit., p. 29. 
presidencial; un partido que estuvo en el poder por 75 años retorna; un ataque a los gobiernos emanados del PAN, partido de la acción nacional, que fundara Gómez Morín, donde la frivolidad -en muchos casos- y el mantenimiento de prácticas de corrupción o caciquiles tienen a la nación dividida. Prevalece la desigualdad social, la pobreza de millones y la miseria de los indios. Si somos fieles a nuestro pensador, no hay una ideología común, no hay coordinación de los esfuerzos y tampoco caminamos juntos. Lo que existe es el dolor en México.

\section{El dolor}

“¿Podríamos, así, hallar un elemento primordial y objetivo para el juicio, un propósito provisional para orientar la acción?

Entre las doctrinas opuestas, a su pesar y causado por ellas a menudo, hay un hecho indudable: el dolor humano.

El dolor de los hombres es la única cosa objetiva, clara, evidente, constante.

Y no el dolor que viene de Dios, no el dolor que viene de una fuente inevitable, sino el dolor que unos hombres causamos a otros hombres...

Y por esta primera razón podemos adoptar el dolor como criterio provisional de verdad; la lucha contra el dolor como campo común de trabajo y discusión.

[...] Socialmente, por lo menos, nuestro deber es obrar, remediar males, mejorar la condición de los hombres". ${ }^{14}$

El dolor es la única verdad que reconocemos de inmediato. Por tanto, hace falta una teoría del dolor que sostenga tres premisas. El dolor es el dolor de los hombres; es el dolor como daño que nos hacemos unos a los otros; y es resultado del individualismo atroz. La vida en sociedad nos dice cómo responder y corresponder, nos disciplina para ver por los otros. Implica saber que dependemos de otros y que damos y recibimos al mismo tiempo; por lo que vivir en el absurdo es pretender que son válidos los actos u omisiones que engendran sufrimien-

${ }^{14}$ Op. cit., pp. 30-1. 
to en otros hombres. Visto así, no se justifica la riqueza de pocos ante la miseria de millones. Tampoco la depredación de los medios de vida que afectan la salud de otros. Menos aún las prácticas corruptas que alejan el dinero del trabajo para darlo a cambio de favores. Es muy fácil repetir los vicios cuando se vive en grupo. Es una mecánica que necesitamos romper. Remediar los males, mejorar a los peor situados, es el deber que nos toca a los que tenemos más bienes, y sobre todo, a los que estamos mejor situados. Es a lo que yo llamaría "equidad".

\section{La técnica}

"No gastarnos en academicismo; pero tampoco en ilustrar como comparsa acciones políticas siempre pequeñas, sino revisar urgentemente los conceptos y las instituciones y hacer de nuestra acción una acción ennoblecida, porque sirva a propósitos humanos claros y definidos [...] No positivismo ni pragmatismo siquiera. Es posible otro camino; el de la técnica. [...] Técnica, que no quiere decir ciencia. Que la supone; pero a la vez la supera realizándola, subordinada a un criterio moral, a un ideal humano. ${ }^{15}$

[...] Técnica que no es tampoco positivismo; que conoce y postula otros valores para el conocimiento y para la vida, y sabe la honda unidad que existe entre todas las manifestaciones del espíritu: música y filosofía, ciencia y pintura, arquitectura y derecho.

Investigar disciplinadamente en nuestra vida, ahondando cada fenómeno hasta encontrar su exacta naturaleza tras los externos aspectos artificiales. Disciplinadamente, también, inventariar nuestros recursos y posibilidades". ${ }^{16}$

${ }^{15}$ Esa es una de las ideas de Caso cuando plantea la existencia como desinterés, que se aboca a la vida como tal, más allá de la labor de la inteligencia o de la razón (que era el quietismo positivista). Dice Antonio Caso: "Las leyes de la adaptación, de la herencia y de la lucha, que juntas producen la selección natural, sirven para la explicación económica de muchos aspectos de la existencia; pero no los explican todos. No obstante, la inteligencia persiste en su tendencia monista, en su línea del menor esfuerzo, y, lejos de confesar su imposibilidad de explicar por principios económicos la actividad desinteresada, tiende a referir toda experiencia a una sola de sus formas, todo ser a un solo aspecto del ser, sin recordar que no existe la realidad para ser explicada por la ciencia, sino la ciencia para interpretar, lo menos imperfectamente posible, la realidad multiforme y diversa", op. cit., pp. 22-3.

${ }^{16}$ Op. cit., p. 33. 
En efecto, la técnica es hija de la ciencia. Y debemos aprender cuáles son los procedimientos que nos llevan a mejorar la vida. Pero lo importante es que se subordine a un fin moral superior. La ciencia ha de generar una técnica que permita ordenar moralmente la vida de los hombres. No se trata de ir acumulando conocimientos sin término; o de pensar que las leyes son inmutables y absolutas, de suerte que el estudiante conozca las leyes y de modo automático transforme la realidad. Más allá del pragmatismo y del positivismo necesitamos de las artes, la filosofía, el derecho, que den paso a la intuición de la que ya se ha hablado: la que une el saber hacer con la perplejidad, la que liga lo que es útil a lo que es un fin en sí mismo, y así, alcanza el estatuto de poder elegir, conocer y saber cuál es el fin remoto al que tendemos como pueblo y nación. Y ese fin es el progreso humano, la realización de nuestras potencialidades. De modo que, siguiendo las ideas de Vasconcelos, lo que Gómez Morín plantea es la necesidad de conocer las ciencias, manejar las técnicas y, por medio de las humanidades y bellas artes, alcanzar el orden moral de una sociedad más justa. El rechazo al craso positivismo simplista o el pragmatismo estéril, es su compromiso como parte de una estrategia: sabiendo que México existe y que venimos de las turbulencias, logremos pacificar los ánimos, evitar las dispersiones y encontrar las convergencias que nos ayuden a intuir la vida y hacer, entre todos, algo por mejorar moralmente al país.

\section{Argumentos}

“-Alas y plomo... ${ }^{17}$

${ }^{17}$ Ezequiel A. Chávez, gran amigo de Manuel Gómez Morín, también habla de volar realizando los proyectos, aterrizando el saber a lo real, por romántico que parezca. Nos dice Chávez: "¡Idealistas que os empeñáis en la salvación de la República, volved los ojos al suelo de México, a los recursos de México, a los hombres de México, a nuestras costumbres y nuestras tradiciones, a nuestras esperanzas y nuestros anhelos, a lo que somos en verdad! Sólo así nos conduciréis a un estado mejor y nos redimiréis de nuestro infortunio [...] Sin aspirar a algo mejor se retrocede sin remedio; pero sin saber con precisión adónde se va, se fracasa, sin duda. "Alas y plomo"; tal ha de ser el lema de nuestra redención ambicionada! La gravedad de la materia pondera la intrepidez del pensamiento, ¡México: Alas y Plomo!”, 2002, México, en Ezequiel A. Chávez, Obra filosófica y autobiográfica II, segunda parte, epígrafes, recopiladora Ma. Del Carmen Rovira Gaspar, El Colegio Nacional, p. 30. 
-Pero no ya la recomendación cobarde del tiempo en que sólo las alas sin plomo podían volar.-Ahora, "alas y plomo" hacen posible el vuelo-. Y el consejo, a la vez, es ejemplo que muestra el valor de la técnica.

Sin embargo, para algunos la actitud propuesta peca seguramente de ambición. Para otros, en cambio, es limitada y cobarde.

El valor no estriba en lanzarse a la empresa quimérica, sino en el caudal de energía y vigor espiritual necesario para mantener siempre vivo el impulso de realización.

\section{Prevenciones}

"Podría decirse generación de 1927 o de 1930, como se dice generación de 1915. Hasta sería más exacto para algunos. Pero 1930 podrá ser el tiempo de la mayor edad o simplemente un año cualquiera de esfuerzos y vicisitudes, mientras 1915 fue el año de la iniciación.

[...] Muchas cosas han cambiado desde entonces entre nosotros y fuera de nosotros [...] Y no nos conforma ya aquella explicación simplista que sólo ve en México dos grupos: la minoría espiritualmente dirigente, de origen o de cultura europeos, y la mayoría 'actuante', indígena o simplemente bárbara. Proclamamos nuestra substantividad.

[...] Nuestro mexicanismo es todavía más un nacionalismo de alfarería que de cultura. Y cuando quiere ser serio, está preñado de temibles amenazas de regresión". ${ }^{18}$

Si hay realmente un sentido estético, una tabla moral y un anhelo interior que determinen una producción artística, una forma de vida-dice Gómez Morín-, una organización social y un espíritu religioso mexicanos, no aplicaremos modelos extraños, sino los nuestros. El orden en que pone las cosas no necesariamente significa que el arte funde la moral y luego lo social. Pero sí hace determinante el sentido de producción de una se-

${ }^{18}$ Op. cit., p. 35. 
cuencia en el planteamiento del problema. Primero necesitamos dejar de lado la distinción entre la minoría criolla de origen europeo y la mayoría india o mestiza como una distinción correspondiente a la de gobernantes y gobernados. Y al mismo tiempo abandonar la idea de que tenemos que ser réplicas de modos extranjeros. Hay que encontrar la substantividad mexicana. Para eso debemos desarrollar un sentido estético, un orden moral, un anhelo interior que determinen una producción artística, una forma de vida, una organización social y un espíritu religioso. El sentido estético tras de la producción artística; la tabla moral tras las formas de vida; y el anhelo interior tras la vida religiosa y el orden social. Se puede preguntar, ¿qué entiende Gómez Morín por “anhelo interior”? Tiene que ver con la confianza en nosotros mismos, el apego a la vida, la adhesión al flujo de vivir vinculado a los otros.

\section{Necesidad de ser lógicos e intuitivos}

"Crítica y método; lo que no quiere decir matar la vigorosa espontaneidad característica de este momento ni significa olvidar que 'el hombre es la medida de todas las cosas'.

Atentos a la vida y al pensamiento; pero que no se torne la actitud en complacencia de espectador ni en dilettantismo vacío.

Pensar y obrar. No lejos de la pasión, dentro de la vida. Evitando igualmente la fácil falsedad de la esquematización y la vana disculpa de un romanticismo inerte.

[...] Lógicos e intuitivos. Serenos y entusiastas. Convencidos y escépticos. Todo según la actividad y el momento". ${ }^{19}$

\section{Epílogo}

"El dolor puede ser un inseguro criterio para valorar la acción. La técnica resultará un débil sistema de trabajo, ya que hasta el nombre induce a confundirlo con el mero procedimiento, con la receta para

${ }^{19}$ Op. cit., p. 36. 
obrar. El hecho mismo de proclamar que somos una generación, puede ser falso.

[...] He tratado solamente de señalar un hecho y de indicar una posibilidad: la posibilidad de encontrar un medio para reunir las buenas voluntades dispersas, los entusiasmos contradictorios y para definir la insoportable angustia que ahora nos agota; el hecho de que hay una multitud de gentes que podrían trabajar juntas en vez de negarse y combatirse; de que hay una orientación, una razón de ser común en los acontecimientos que, en confusión terrible y sin aparente sentido, ocurren en México. ${ }^{20}$

[...] Esta es nuestra situación, esta es nuestra responsabilidad. No pensemos que somos mejores que otros ni consintamos en parecer peores. Sólo podemos estar destinados a ser diferentes. No hacernos ilusiones paradisíacas ni permitir que se prediquen nuestros desastres. [...] El deber mínimo es el de encontrar, por graves que sean las diferencias que nos separen, un campo común de acción y de pensamiento, y el de llegar a él con honestidad -que es siempre virtud esencial y ahora la más necesaria en México.

Y la recompensa menor que podemos esperar, será el hondo placer de darnos la mano sin reservas.

México, febrero de 1926". ${ }^{21}$

Cuatro son las premisas fundamentales en relación a la idea del pensamiento crítico que busca el pensador. Lo primero es, como se ve, que no basta pensar. Hay que obrar apasionadamente y con entusiasmo. ¿Cuántas acciones realizamos sin pasión? ¿Hasta dónde hacemos lo que hacemos por inercia? Muchas son las acciones que realizamos como parte de lo que hacemos todos los días, por rutina, hábito, burocratización. Es tiempo de que hagamos las cosas con pasión, enamorados de lo que hacemos. Y eso significa tener el impulso, el deseo generoso de que haya menos planes, programas, diseños sobre la mesa, y más trabajo a partir de pocos programas, pero viables. Eso permite que con serenidad estemos convencidos, sin dogma, de que podemos llegar a lo que buscamos: es el

${ }^{20}$ Op. cit., p. 37.

${ }^{21}$ Op. cit., p. 38. 
camino de la intuición. La lógica tras el pensamiento; convicciones sin dogmas. Impulso entusiasta. Eso es lo que México necesita.

Por último, tenemos que dejar de negarnos unos a otros. De combatirnos todo el tiempo. El ninguneo mexicano. En su lugar, trabajar juntos. Colaborar con los otros sabiendo que ellos colaborarán con nosotros. Necesitamos un sentido de orientación porque, por momentos, parece que vamos en confusión y sin un sentimiento común. Ocurre en México que vivimos como si no existiera brújula; en 1926 como en 2012. Tal parece que las ideas de Manuel Gómez Morín siguen vigentes.

\section{La Universidad de Mexico. Su Naturaleza Jurídica} Mexico, D.F. septiembre de $1934^{22}$

“En suma, la Universidad Nacional de México es una institución corporativa, del más alto nivel público, que tiene como fin propio y exclusivo una función esencial para la Nación; está dotada de autonomía para organizarse sobre las bases generales que señala la Ley, y para decidir por sí misma cuanto se refiere al cumplimiento de su finalidad específica...

No es un Estado soberano, y por eso no está sujeta, en todo lo que queda amparado en su estatuto autónomo, a la actividad y al poder de decisión del Estado: derecho común sobre propiedad, posesión, disfrute, adquisición o disposición de bienes, y sobre obligaciones o contratos; leyes, reglamentos y disposiciones generales, administrativos y de policía y de buen gobierno; decisiones judiciales en los casos en que la Universidad sea parte.

Tampoco es una empresa privada para fines de lucro, para fines indiferentes o para fines de interés público no reconocidos por el Estado mismo como esenciales a la vida de la comunidad, sino que existiendo desde antes como una Institución del Estado Federal para cumplir una misión esencial a la vida de la República, ha recibido del mismo

${ }^{22}$ Este texto también está recogido en Manuel Gómez Morín, 1915 y otros ensayos, 1973, México, Editorial Jus. Todos los encabezados en cursivas son de Gómez Morín, y deliberadamente los dejo como marcas que inician sus textos. La idea es que hable Manuel Gómez Morín. 
Estado, sin un cambio de la finalidad que le es propia, la forma de institución autónoma [...] que le fija la Ley de autonomía". ${ }^{23}$

Es importante que se insista -sobre todo en ese año de 1934-que la Universidad es autónoma. Es una institución que tiene sus propios reglamentos, administración, forma de organización, disposiciones para maestros y alumnos, mecanismos para la elección de sus dirigentes. Pero eso no significa que sea un Estado soberano frente al Estado del que forma parte. Es una institución del Estado subordinada a la Ley. En ese sentido, Gómez Morín es enfático: la Universidad tiene un reglamento propio, subordinado siempre a lo que la ley marca en cuanto al derecho común sobre propiedad, posesión, disfrute, adquisición o disposición de bienes, y sobre obligaciones o contratos; leyes, reglamentos y disposiciones generales, administrativos y de policía y de buen gobierno; decisiones judiciales en los casos en que la Universidad sea parte. La mención de las disposiciones administrativas y de policía nos indica que la autonomía universitaria no significa que al interior de su vida no priven las normas que se aplican en la comisión de delitos. No es un estado de excepción. Pero tampoco es una empresa que se organiza desde su registro ante la secretaría del trabajo con los fines de producción de bienes, la ganancia y el empleo. Su fin no es el lucro y su misión es educar, formar personas de bien para la sociedad. Siempre desde una estructura autónoma.

Su funcion social y la razón de ser de su autonomía I. Afirmación de la autonomía

"La Universidad tiene un claro destino social: lograr en cada uno de sus momentos ese fruto complejo y riquísimo en su heterogeneidad, que es la cultura; divulgar lo más ampliamente que sea posible, los frutos culturales alcanzados en la investigación y en el estudio, y dar a la comunidad técnicos bien preparados que se encarguen de sus servicios.

Hay en la sociedad otras misiones tan interesantes como la reservada a las instituciones universitarias: la misión de hacer justicia, la de elaborar el derecho positivo, la de organizar la economía nacional,

${ }^{23}$ Op. cit., pp. 84-5. 
la de impedir o remediar los males de una defectuosa organización económica y política. A cada uno de esos propósitos responden o deben responder instituciones adecuadas para alcanzarlos.

[...] la Universidad no es una institución aislada de la comunidad, sino que está hondamente arraigada en ella, unida a las demás instituciones sociales estrechamente, y obligada por su esencia misma a revertir sobre la sociedad entera el fruto integro de su trabajo". ${ }^{24}$

Los problemas del país son enormes. Tienen que ver con la organización del campo, el diseño de las políticas públicas, el sistema económico y las reformas que necesite, amén de garantizar la administración de justicia, la paz social. Claro que la Universidad no es ajena a la comunidad: es parte pensante de esos problemas, de modo que su misión es estudiarlos, investigarlos, ofrecer soluciones al Estado, ${ }^{25}$ a las empresas, a las instituciones que se encargan en suma de resolver esos problemas. Dentro de su autonomía el fin primordial es la cultura, y el estudio de los problemas nacionales. Y hacerlo con plena autonomía. En cuanto a la ciencia, nos dice Gómez Morín:

\section{La naturaleza de la labor científica}

"Es fundamental reiterar la afirmación de que ni en las ciencias, ni en la Filosofía, el conocimiento puede estimarse completo y definitivo.

Las nociones científicas de más firme apariencia, aun en aquellas ramas de la actividad científica más antiguas y exploradas como las Matemáticas, están sujetas a revisión. Los progresos de la técnica y de la investigación invalidan doctrinas que parecían firmes y abren nuevos horizontes de interpretación y de elaboración doctrinal, en Física, en Química, en Biología. Las concepciones filosóficas sufren la crítica resultante de las aportaciones nuevas de las ciencias, además de estar

${ }^{24}$ Op. cit., p. 93.

${ }^{25}$ Ezequiel A. Chávez también comparte la importancia de la Universidad en el sentido de su función social. Dice Chávez: "La razón social de la creación de la nueva Facultad de Ciencias, es obvia. Saber es poder. Quien no sabe no puede. Si no se cultiva la alta especulación científica en la Universidad de México, seguiremos siendo los súbditos de los pueblos y las universidades que sí saben cultivarla en su seno", op. cit., pp. 105-6. 
sujetas a una incesante labor de rectificación y de renovación debida a la crítica filosófica misma.

Las ciencias sociales, de tan reciente iniciación que no pasan aun del período de planteamiento de problemas, de búsqueda de métodos, se encuentran por supuesto no sólo sujetas a esta ley de rectificación, sino que por su juventud, por la falta de medios experimentales, por la deficiencia de las posibilidades de observación, están más lejos todavía que las viejas disciplinas, de alcanzar conclusiones definitivas.

La labor característica del pensamiento, por otra parte, ha sido y será siempre la de incesante revisión de su propia obra. Y el período actual de elaboración científica, jurídica o filosófica, es esencialmente un período de crítica, bien lejano de las épocas en que pueden darse por ciertas, con relativa firmeza, algunas de las nociones esenciales del conocimiento". ${ }^{26}$

La Universidad enseña las ciencias a los estudiantes; pero comprende que si algo se corrige constantemente es el acervo de conocimientos que integran las ciencias. Las teorías se confirman en la experiencia; las rectificaciones constituyen la esencia del sentido crítico. Y ese sentido es el que la Universidad debe infundir en sus estudiantes: la capacidad de cuestionar, poner en duda, analizar, rectificar las tesis que sustenten. Por lo que toca a las ciencias sociales, su naturaleza las ubica en una posición diferente a la de las ciencias duras. La sociología no es la física. Incluso el planteamiento de los métodos de estudio es algo abierto, en revisión. Mientras las ciencias duras tienen una idea clara del llamado método de investigación de que se valen (hay un método científico más o menos normado), las ciencias sociales buscan su método, lo cambian de acuerdo al tema de estudio, y se corrigen más. La disposición a rectificar es muy importante en ciencias sociales. Por supuesto, la filosofía se estudia contemplando la necesidad del rigor crítico y el constante preguntarse por la naturaleza de las cosas. Ya nada puede darse por cierto: no son tiempos de dogmatismo, fanatismo, cerrazón. El diálogo entonces se abre paso; los argumentos demandan ser escuchados; el intercambio de argumentos es el camino de revisión de las obras, siempre

${ }^{26}$ Op. cit., p. 94. 
inacabadas. Pero el saber enseñado debe tener aplicación en la vida práctica. Nos dice Gómez Morín:

"Sin embargo, para los fines prácticos, para la acción, el ingeniero, el electricista, el médico, el hacendista, pueden obrar con apoyo en las conclusiones provisionales de las ciencias respectivas, dando pragmáticamente carácter de verdad definitiva a lo que no es sino hipótesis sin comprobación plena. Pero el matemático, el físico, el químico, el biólogo, el economista, no pueden ignorar para su estudio la provisionalidad de sus conclusiones ni cerrar los ojos ante los datos que para la elaboración de una nueva doctrina o para la rectificación de las tesis anteriores, resultan de la investigación positiva y de la crítica metódica.

[...] Pero cuando, como sucede en la Universidad, no se trata de ejecutar ni de decidir, sino de buscar y de estudiar, el procedimiento es precisamente inverso y requiere como queda dicho, consideración objetiva, análisis y cotejo de fenómenos y explicaciones, porque de lo contrario en vez de un fruto maduro de conocimiento, se obtendría el mezquino resultado de una mera repetición rutinaria y desvitalizada, sobre todo en los aspectos superiores de la cultura, en los que por definición es indispensable admitir la relatividad del saber y la posibilidad de su ampliación por rectificación constante", ${ }^{27}$

La Universidad está destinada a investigar, a estudiar, a criticar; necesariamente debe proclamar como base de su trabajo la perfectibilidad del conocimiento y la necesidad ineludible de la rectificación. Por lo tanto, el saber es relativo, revisable, si acaso quiere ampliarse y crecer. El lugar donde se respira la libertad para pensar, dudar, rectificar, es la Universidad. Por ende, un alumno educado siempre es crítico. Ahí donde la cátedra consiste en que el estudiante repita lo que dice el texto, se aborta la misión universitaria: pensar.

${ }^{27}$ Op. cit., pp. 95-6. 


\section{La universidad desorientada}

“¿Quiere decir esto, como algunos políticos pretenden, que por reconocer que no existe absoluta uniformidad respecto a las conclusiones de las ciencias, del Derecho, de la Filosofía, la Universidad está desorientada?

Evidentemente no. Está desorientado el que no sabe lo que quiere o el que ignora los medios de que dispone para cumplir su propósito. Y la Universidad sabe bien lo que quiere, conoce y acepta su destino en la comunidad y no trata de ocultar, antes empieza por proclamar, que los medios específicos adecuados para cumplir ese destino son limitados y relativos.

La Universidad quiere y debe querer realizar una obra de cultura ${ }^{28}$ y sabe que esa obra resulta no de la afirmación arbitraria, sino del examen objetivo de los fenómenos, de la crítica libre y sagaz de las doctrinas y de las instituciones, porque la cultura es eso justamente: el producto homogéneo, la trama uniforme que resulta del cruce y del cotejo de explicaciones y de críticas, de interpretaciones antiguas y de hechos nuevos". ${ }^{29}$

\section{Los organismos de acción}

"En la comunidad han de existir diversos organismos de acción, instituciones orientadas exclusivamente sobre una creencia, partidos políticos, agrupaciones confesionales, corporaciones de toda índole expresamente instituidas para promover la realización o la propaganda de ideas que se ofrecen al público como explicación completa de la vida o como solución definitiva de los problemas sociales". ${ }^{30}$

${ }^{28}$ Antonio Caso habla de la cultura como misión relevante de la Universidad. Dice Caso: "México es, inconcusamente, uno de los grandes pueblos históricos. Las magníficas civilizaciones precortesianas -tan admiradas hoy en el mundo- deberán ser objeto preferente de interés para los alumnos universitarios. La nueva organización querría colaborar en este esfuerzo, que tanto distingue a la cultura mexicana. Lingüistas y arqueólogos hallarán en las clases que se impartan, elementos para dar pábulo a su dedicación....”, en Antonio Caso, Apuntamientos de Cultura Patria, 1943, México, Imprenta universitaria, p. 112.

${ }^{29}$ Op. cit., p. 96.

${ }^{30}$ Op. cit., p. 97. 
Cuando se teme al libre pensamiento en la Universidad se teme a la posibilidad de que no se acepte un dogma impuesto por razones de Estado. Es decir, no puede ser que el Estado le diga a la Universidad lo que debe, puede y tiene que enseñar a sus estudiantes. Imponer una doctrina a la juventud es matar el sentido de la Universidad. Eso sucede en los países comunistas, en las formaciones religiosas integristas o en escuelas donde la crítica no se tolera.

\section{Orientación y fin social}

"La Universidad tiene y quiere un fin muy claro y muy definido, ese sí exclusivo y único. Es un fin de servicio a la comunidad. Esta ligada con las más limpias y más elevadas aspiraciones de íntegro mejoramiento humano. Jamás podrá alzarse en contra de ese fin, porque él es la substancia misma del trabajo universitario y sin él la Universidad no tiene razón alguna de existir.

Pero precisamente para cumplir ese fin exclusivo, la Universidad está en el deber de conservarse como un campo libre, abierto a la discusión, condicionado solamente por la objetividad y por la honestidad en los que en ella trabajan". ${ }^{31}$

\section{El carácter del trabajo universitario}

'No puede olvidarse, por otra parte, que la labor en la Universidad tienen necesariamente un carácter facultativo, voluntario. Requiere cualidades de atención, de devoción, que no sólo no pueden ser logradas por fuerza, sino que a menudo implican positivo espíritu de sacrificio.

No es posible pensar en la labor del investigador ni en la del alumno, si no se fundan en un deseo voluntario de conocer. Y si del profesor se quiere obtener algo más que el cumplimiento externo y deprimente

${ }^{31}$ Se ve claramente que Manuel Gómez Morín concibe la Universidad como parte esencial de la razón de ser de una sociedad, es imposible envilecerla o desfigurarla mediante el dogmatismo, la deshonestidad o la falta de objetividad en la visión de las cosas. Mejorar la condición humana, la libertad y el espacio de diálogo es el objetivo nodal de la universidad. 
de una mala rutina, es preciso contar con su vocación, con su adhesión cariñosa a la labor que se le ha confiado". 32

Sin duda el estudiante que padece profesores que no se actualizan es lo peor que puede ocurrirle. No solamente porque el profesor no profesa vocación y entusiasmo, sino porque no es literalmente profesor, es un burócrata que cumple, asiste, repite, va todos los días a la mala rutina, que es justo la que se despliega cuando solamente convierte la actividad académica en una trabajo pesaroso. Dada la misión universitaria, Manuel Gómez Morín agrega la necesidad de devoción, afecto, entrega, vocación, y voluntad desde el espíritu de sacrificio de sus docentes. Aparte queda la necesidad de que, además, investiguen. ¿Es mucho pedir del trabajo universitario? Lamentablemente, entonces y ahora hay muchos profesores de mala rutina, pocos enamorados de lo que hacen. $\mathrm{O}$ que lo hacen sin pasión y anhelo interior.

\section{Razones históricas de su autonomía}

"Ni el Estado tenía un control cierto sobre la Universidad, ni ésta podía ocuparse eficazmente de su organización. En cambio, el ambiente y los hábitos de lucha creados por una subordinación ineficaz a las autoridades administrativas, se extendieron a todos los sectores de la vida universitaria rompiendo en sus aspectos más esenciales los móviles verdaderos del trabajo y trayendo consigo una serie de consecuencias secundarias muy graves respecto de la actividad docente y, sobre todo, respecto de la formación moral de los alumnos.

Esta situación fue reconocida expresamente por el Estado en 1929, e invocada por él en 1933 para la proclamación completa de la autonomía, con la afirmación exacta de que el problema universitario y su solución adecuada no son cuestiones de fuerza ni dependen de la imposición autoritaria de ciertas normas, sino de la crea-

${ }^{32}$ Es evidente que la relación entre alumno, profesor e investigador debe fundarse en la vocación de hacer cada uno lo que debe con gusto. 
ción de actitudes y propósitos encaminados al logro de la obra común de cultura". ${ }^{33}$

\section{Esencia de la autonomía}

"La autonomía no es, pues, un capricho. En su forma más alta de libertad de investigación y de crítica, resulta impuesta por la naturaleza misma de la Universidad, por el fin a que esta Institución corresponde en la sociedad, por el carácter de su trabajo [...] Y la autonomía no significa ni podrá significar un absurdo desgarramiento entre la Universidad y la comunidad de que forma parte, una pretensión ridícula de soberanía, un alejamiento monstruoso de la sociedad que la ha creado para su propio bien.

Autonomía no implica aislamiento, como algunos argumentan. La Universidad no vivirá distante de las necesidades y de los anhelos de los hombres, ni al margen de sus dolores o de su esperanza. Estará en medio de la vida social, sensible como ningún otro instituto, no sólo a las grandes fuerzas visibles que agitan a todos los hombres y a todas las mujeres, sino también a la creación, al descubrimiento y la crítica individuales que han de tornarse después en fuerzas de la colectividad. Dentro de lo actual; pero proyectada al futuro y entrañablemente unida al pasado. ${ }^{34}$

\section{La negación. La enseñanza contradictoria}

"Con mayor ignorancia aún se dice que la libertad de cátedra, permitiendo la contradicción, estableciendo la controversia, impide la educación del alumno, le hace imposible la formación de un criterio.

¡Como si la controversia no fuera, justamente, el camino mejor en la enseñanza y en la justicia y en la política, para lograr conclusiones razonables!

${ }^{33}$ Op. cit., pp. 100-1.

${ }^{34}$ Op. cit., pp. 101-2. 
¡Como si la formación de un criterio adulto fuera cosa de admitir a ciegas una explicación o una doctrina ignorando sus críticas y desconociendo las otras posibilidades que la vida del pensamiento ofrece! [...] sin la posibilidad de contradicción, la Universidad resulta inútil e inconcebibles la obra intelectual y la vida decorosa. Si la controversia es un mal, precisa prohibir los congresos, las asambleas, las reuniones de toda clase, y considerar de paso las bibliotecas, como institutos de corrupción social". ${ }^{35}$

La misión de la Universidad en su esencia autonómica es concebirse como parte de la comunidad, no ajena a ella. Capaz de atender los problemas que hay en la comunidad, y al mismo tiempo, proponer soluciones. Siempre a partir del espíritu crítico que debe haber en las aulas. Quienes ven la controversia como contradicción, y la contradicción como enfrentamiento con el Estado, no entienden lo que significa la libertad de cátedra. La riqueza misma del debate, el choque de opiniones, hace avanzar el conocimiento. Para eso son los congresos, simposios y asambleas. La Universidad es cuna esencial del diálogo. Si el Estado -como Gómez Morín ve en 1934-, quiere imponer un modelo de educación a la Universidad, es preciso defender la libertad por medio de la autonomía.

\section{Razones para una mala preparación}

“También se alega que la universidad está produciendo profesionistas inútiles en vez de formar técnicos para atender con eficacia las necesidades de la sociedad.

Y bien, éste es un mal denunciado desde hace muchos años, que no depende de la libertad de crítica y del que, en todo caso, es principalmente responsable el Estado mismo, ya que bajo su control ha estado la Universidad.

${ }^{35}$ Gómez Morín defiende la contradicción como confrontación, enfrentamiento, disyunción, copresencia, variedad y diversidad de puntos de vista, opiniones y creencias, juicios y teorías. El diálogo no puede ser dogmático y menos aún fundamentalista; si así fuera, no habría sentido crítico ni vida pensante. 
En efecto, la preparación profesional que ha dado la Universidad es mala por tres razones: La primera, porque es técnicamente insuficiente; la segunda, porque esta orientada a un número tradicional de actividades como olvido de muchas otras funciones técnicas que la sociedad moderna reclama; la tercera, porque un buen número de los alumnos preparados en la universidad, han ido a la vida más dispuestos a una función individual de ganancia, que a una función general de servicio". ${ }^{36}$

Entonces, fracasa la enseñanza y se prepara mal a los estudiantes por tres razones: a) la institución no dispone de las herramientas técnicas adecuadas a la docencia e investigación (falta de equipo, malos laboratorios, aulas en mal estado: hoy serán malas computadoras, fallas en la red, ruido, bibliotecas mal equipadas y con acervos raquíticos, burocratización, desconocimiento de los usos digitales, falta de imprenta para publicar los libros de los profesores); b) desconocimiento de las nuevas tecnologías, $\mathrm{y}$, por lo mismo, nula actualización de profesores y alumnos en relación a lo que avanza el mundo; c) fomentar el afán de lucro en los estudiantes, y no el amor a la lectura, la cultura y el estudio. En eso, como siempre, Gómez Morín pone el dedo en la llaga, porque precisamente los estudiantes mexicanos, en pleno siglo XXI, salen mal preparados por esas razones: no se ha resuelto el problema.

\section{Posibles soluciones}

"De esas tres causas, la primera no se remedia con órdenes de autoridad, sino con buenos planes de estudios, con buenos profesores, con buenos métodos de enseñanza, con laboratorios más completos y bibliotecas más vivas, con un acendramiento de la disciplina, del orden, del amor a la cultura en cuantos trabajan en la Universidad, alumnos, profesores o investigadores.

La segunda causa tampoco se evita con acuerdos de un ministro, ni donde la adopción de una doctrina única. Es, también, asunto técnico en

${ }^{36}$ Op. cit., p. 109. 
cuanto se refiere a planes de estudios y a capacitación para profesiones nuevas, asunto social en cuanto entraña la necesidad de hacer atractivos los estudios necesarios para esas nuevas actividades profesionales.

Finalmente la tercera razón, la más frecuente, y la más frecuentemente invocada como argumento para destruir la Universidad, más que un defecto universitario es fundamentalmente un asunto que deriva de la estructura social. ¿Cómo exigir, en efecto, que los estudiantes de la Universidad al salir de la aulas, con un fervor apostólico que no existe en ninguno de los otros sectores sociales, se dediquen de modo exclusivo al servicio público cuando la lucha por la ganancia, que es la forma de organización social contemporánea, los obliga fundamentalmente a trabajar para ganar, y cuando toda la estructura del Estado actual los orienta a pensar en el poder económico como uno de los objetivos esenciales para su actividad?". ${ }^{37}$

Las ideas que siguen responden a la necesidad de que la Universidad, coherente con el sentido de la Revolución mexicana, luche contra la imposición del modelo socialista como único, y el marxismo como única doctrina, desde la cual enfrentar o vislumbrar los problemas

102 nacionales. Eran los tiempos en que el proyecto cardenista buscaba esa imposición doctrinaria, y por eso el régimen veía a la Universidad como sede de reaccionarios, conservadores, tradicionalistas. Con firme espíritu liberal, Manuel Gómez Morín defiende la libertad de cátedra dentro del marco de la Revolución:

"Se dice también que la Universidad es refugio de reaccionarios, porque la libre opinión permite enseñar como ciertas, doctrinas muertas ya; porque en la Universidad se profesan tesis contrarias al mejoramien-

${ }^{37}$ Op. cit., p. 110. Manuel Gómez Morín admite que hay profesionistas mal preparados en México, por tres razones: son técnicos no aptos para resolver las necesidades de la sociedad o atenderlas; o son técnicos que no han tenido el acceso a planes de estudios, carreras alternativas, bibliotecas dinámicas, que les permitan adaptarse a una sociedad moderna y, por supuesto, con necesidades que demandan soluciones basadas en herramientas más complicadas tecnológicamente; o finalmente son estudiantes que sólo buscan en la vida la ganancia y el poder y, por ende, no estudian ni hacen el bien para servir a los demás. 
to humano o se divulgan críticas en contra de la organización política actual; porque de la Universidad forman parte enemigos naturales de la Revolución.

Este es, por supuesto, repetido en todos los tonos de la gastada literatura política, el argumento principal del ataque contra la Universidad..$^{38}$

Los millares de alumnos que están ahora en la Universidad y los que han estado antes de ellos, pueden dar testimonio de que fuera de algunas asignaturas especiales, los profesores tienen especialmente la preocupación debida de su técnica y limitan a la enseñanza de esa técnica su actuación escolar, sin perder el escaso tiempo señalado en los programas, en exposiciones de carácter político o social". ${ }^{39}$

\section{Una juventud inadaptada}

"En cuanto a los alumnos, aparte de que su juventud misma es garantía de un espíritu de inadaptación al medio y de inconformidad, científicamente también, la estadística demuestra que en un sesenta por ciento de los casos, los estudiantes de la Universidad proceden de familias de maestros, de obreros, de campesinos, de empleados, y que del cuarenta por ciento restante, la inmensa mayoría vienen de familias que viven de un salario extraordinariamente modesto y escasamente suficiente para la vida de los numerosos miembros de la familia que la integran.

${ }^{38}$ Op. cit., pp. $110-1$.

${ }^{39} \mathrm{Op}$. cit., pp. 111-2. Es evidente que Gómez Morín escribe en una época en que el régimen persigue a los opositores a la "Revolución"; la Universidad es nueva en sus afanes, pero sobre todo abunda la necesidad de separar lo político de lo académico. El temor de suponer que las universidades son semilleros de revoltosos no se extinguió; al contrario, incluso ahora en estos tiempos, del año 2012, se acusa a los jóvenes de porros o antisociales si se expresan a favor o no de un proyecto político o de un candidato. Lo importante es que se reconozca el rigor científico, la libertad de cátedra; pero, por lo mismo, que esa libertad no se use para politizar desde las aulas. Manuel Gómez Morín defiende el sentido profesional de docentes y alumnos dedicados a la reflexión. Pero llama mucho la atención que lo diga justo en tiempos de Calles; ¿será una vacuna contra el régimen autoritario del general revolucionario y de otros por venir? Sabemos que Lázaro Cárdenas no quería mucho a la Universidad, y que siempre apoyó la formación técnica por encima de las humanidades, justo por el temor al pensamiento diverso, disidente, libre, complejo. Las notas de Gómez Morín cobran hoy gran actualidad. 
Por eso la Universidad, a pesar de necesitar ahora imperiosamente la cooperación económica de los alumnos, para no cerrar a nadie sus puertas por causas pecuniarias, ha debido exceptuar de pago a millares de estudiantes incapacitados para cubrir sus cuotas o ha reducido el monto efectivo de éstas a sólo un por ciento de su importe en la gran mayoría de los casos". ${ }^{40}$

\section{Las doctrinas muertas y la enseñanza antisocial}

"En cuanto a que la Universidad profese doctrinas antisociales, contrarias al mejoramiento humano, sólo debe decirse que tal afirmación no es sino el aspecto más vil de la maquinación política que se pretende urdir en contra de la Universidad y de su trabajo.

Por su esencia, entre todas las instituciones sociales, la Universidad es la que más limpiamente, sin sombra de interés económico o político, ha de dedicarse siempre, por sus propios caminos, a la obra de mejoramiento colectivo". ${ }^{41}$

\section{La orientación de la "orientación"}

"Se dice, sin embargo que esta actitud de la universidad solo sería cierta si se ajustara a una tesis social que los 'orientadores' no han podido definir; pero que vagamente colocan bajo la bandera del socialismo revolucionario. ${ }^{42}$

${ }^{40}$ Op. cit., pp. 112-3.

${ }^{41}$ Op. cit., p. 113.

${ }^{42}$ Manuel Gómez Morín reacciona contra el proyecto socialista del cardenismo y que se convirtió en doctrina oficial del régimen. Lo que Gómez Morín argumentará es la necesidad de una vida mejor para los hombres, de un sentido libre de la existencia, pero no el dogmatismo marxista convertido en doctrina impuesta y que no puede ser criticada; es decir, el propio marxismo carece de la solución a todos los problemas y esta sujeto a múltiples interpretaciones, de modo que la filosofía social orienta a los profesores y alumnos a pensar y cuestionar aquello que concluyen. Con suma prudencia, por la época en la que escribe el texto, se pronuncia por una formación humana y no autoritaria, acepta que el socialismo sea una actitud o convicción racional mas no un catecismo ideológico. 
Quienes hacen esta afirmación, mienten por partida doble: porque no es cierto que la universidad pueda cumplir su destino social atándose a ésa o a cualquier otra doctrina, ni es cierto que lealmente la pretendida 'orientación' implique los postulados en que verbalmente dice apoyarse.

[...] Es bien sabido que cuando el socialismo revolucionario era considerado como un delito por los mismos que ahora de improviso se llaman sus abanderados, ya en la Universidad esa convicción, sus afirmaciones y sus negaciones, eran objeto de atento estudio; que también -y nadie puede negarlo- ese estudio, como los demás que con verdadero espíritu universitario se hagan en la Universidad respecto de todos los movimientos que tiendan al advenimiento de una vida mejor para los hombres, ha sido y seguirá siendo hecho sin odio, ni temor, ni interés pequeño [...] la Universidad misma, como institución, aun cuando por adhesión general de sus miembros a una tesis marxista $\mathrm{o}$ no, tenga como dominante en su trabajo un cuerpo de doctrina acorde con esa tesis, deberá seguir abierta, bajo pena de la muerte peor que es la resultante de abandonar su propio y peculiar destino, al descubrimiento y a la rectificación, al invento y a la crítica, a la reordenación de los conocimientos y a las construcciones nuevas". ${ }^{43}$

¿Qué significa orientar?

“Si se dice que la 'orientación' ha de estribar en dar a los alumnos la noción de que es menester modificar profundamente la estructura social contemporánea y restablecer para la vida valores distintos del provecho económico y de la ganancia, hacerles sentir la necesidad de no considerar aceptables las tesis y las doctrinas que no se apoyen en datos objetivos ni soporte en la crítica nacional, inculcarles el sentido de su trabajo como deber de servicio y no como ocasión de fácil medro, entonces la 'orientación' no traerá nada nuevo a la Universidad actual, porque todo su trabajo se apoya exactamente en esos postulados [...] y en la crítica libre". ${ }^{44}$

${ }^{43}$ Op. cit., pp. 114-5.

${ }^{44}$ Op. cit., p. 116. 
Conviene recordar esta tesis de Manuel Gómez Morín cuando nos habla de orientar a la juventud en tiempos autoritarios, dogmáticos, materialistas. Es preciso que los estudiantes sean orientados correctamente por sus profesores, y eso solamente se consigue si se entiende lo que es orientar. Como vimos, para Gómez Morín la “orientación” ha de estribar en dar a los alumnos la noción de que es menester modificar profundamente la estructura social contemporánea y restablecer para la vida valores distintos del provecho económico y de la ganancia, hacerles sentir la necesidad de no considerar aceptables las tesis y las doctrinas que no se apoyen en datos objetivos ni soporte en la crítica nacional, inculcarles el sentido de su trabajo como deber de servicio y no como ocasión de fácil medro... 